\title{
PROPRIEDADES DE CHAPAS DE AGLOMERADO FABRICADAS COM ADESIVO TÂNICO DE ANGICO-VERMELHO (Anadenanthera peregrina) E URÉIA-FORMALDEÍDO ${ }^{1}$
}

Angélica de Cássia Oliveira Carneiro², Benedito Rocha Vital ${ }^{2}$, Pedro Gustavo Ulisses Frederico ${ }^{3}$, Ana $^{2}$ Márcia M. Ladeira Carvalho² e Graziela Baptista Vidaurre ${ }^{3}$

\begin{abstract}
RESUMO - O principal objetivo deste trabalho foi produzir chapas de aglomerado substituindo-se parcial ou totalmente os adesivos à base de uréia-formaldeído por adesivos de taninos extraídos da casca de angico-vermelho (Anadenanthera peregrina) e hidrolisados. As chapas de aglomerado foram fabricadas com partículas de Pinus elliottii e dimensões aproximadas de $40 \times 40 \times 1 \mathrm{~cm}$, contendo $8 \%$ de sólidos de adesivo em relação à massa seca de partículas, sendo $100 \%$ de adesivo de uréia-formaldeído puro ou contendo $12,5,25$ e 37,5\% de adesivo tânico. Foram produzidas, também, chapas com adesivos tânicos puros, constituindo um total de cinco tratamentos, com três repetições. As chapas foram fabricadas com densidade média de $0,7 \mathrm{~g} / \mathrm{cm}^{3}$. As propriedades físicas e mecânicas das chapas foram determinadas em conformidade com a norma ASTM D-1037 (1993). Os resultados dos testes mecânicos foram comparados com os valores mínimos estabelecidos na norma ANSI/A 208.1-1993 (Wood Particleboard), enquanto os resultados dos testes de absorção de água e inchamento em espessura, comparados com os valores máximos estabelecidos na norma DIN 68m761 (1)-1961. A resistência mecânica das chapas de aglomerado produzidas com adesivos contendo taninos de angico-vermelho, com exceção do módulo de elasticidade, ultrapassou os valores mínimos requeridos na norma ANSI/A1-280/93. A absorção de água e o inchamento em espessura, após 2 e 24 h de imersão, de todas as chapas excederam o valor máximo estabelecido. Conclui-se que os adesivos de taninos de angico-vermelho podem substituir parcial ou totalmente o adesivo comercial de uréia-formaldeído, e as suas misturas são indicadas para uso interior, em que a resistência à umidade não é requerida.
\end{abstract}

Palavras-chave: Taninos, chapas e adesivos.

\section{PROPERTIES OF PARTICLEBOARDS GLUED WITH ADHESIVES OF “ANGICO-VERMELHO” TANNIN (Anadenanthera peregrina) AND UREA- FORMALDEHYDE}

\begin{abstract}
The main objective of this work was to produce particleboards with hydrolysed "angico-vermelho" bark (Anadenanthera peregrina) tannins as partial or total substitute of urea-formaldehyde. Particleboards with the dimensions of 15.75" x 15.75" x 0.39 " were manufactured with Pinus elliottii particles and 8\% of adhesive solids in relation to the dry mass of particles. Adhesives employed either $100 \%$ urea-formaldehyde or 12.5, 25 and 37.5\% of tannin adhesive. Boards were also manufactured with pure tannin adhesives. The experimental design was constituted of five treatments and three repetitions. The particleboards average density was $0.7 \mathrm{~g} / \mathrm{cm}^{3}\left(0.0618 \mathrm{oz} / \mathrm{in}^{3}\right)$. Board properties were determined according to the ASTM D-1037 (1993) standards. The mechanical propertiy values were compared to the minimum values established by the ANSI/ A 208.1 standards. Water absorption and thickness swelling values were compared to the maximum values
\end{abstract}

\footnotetext{
${ }^{1}$ Recebido em 24.08.2007 e aceito para publicação em 24.04.2009.

${ }^{2}$ Departamento de Engenharia Florestal da Universidade Federal de Viçosa. E-mail: <cassiacarneiro@ufv.br>, <bvital@ufv.br>.

${ }^{3}$ Programa de Pós-Graduação em Ciência Florestal da UFV. E-mail: <grazibaptista@ yahoo.com.br>.
} 
established by the DIN $68 m 761$ (1) standards. The mechanical properties of boards produced with the adhesives containing tannins of "angico-vermelho", except for the elasticity module, exceeded the minimum values requested by the ANSI/A1-280/93 standards. The water absorption and thickness swelling of all the boards exceeded the established maximum value after 2 and $24 \mathrm{~h}$ of immersion. It is ended that the adhesives of tannins of angico-vermelho can substitute partially or totally the commercial urea-formaldehyde adhesive and also that their mixtures are suitable for interior use, where resistance to humidity is not requested.

Keywords: Tannins, particleboard and adhesives.

\section{INTRODUÇÃO}

O interesse pelos adesivos, oriundos de fontes naturais, aumentou após a crise do petróleo na década de 1970. A partir dessa data, várias pesquisas foram desenvolvidas com o objetivo de substituir, parcial ou totalmente, os adesivos comerciais convencionais.

Dentre as fontes naturais, destacam-se os taninos vegetais. Segundo Waterman e Mole (1994), provavelmente a definição mais aceitável é a de BateSmith e Swain (1962), que classificaram os taninos vegetais como "compostos fenólicos solúveis em água, tendo peso molecular entre 500 e 3.000 e que, ao lado de reações fenólicas usuais, têm a propriedade de precipitar alcalóides, gelatinas e outras proteínas".

Quimicamente os taninos são separados em duas classes distintas: taninos hidrolisáveis e taninos condensados. De acordo com Ferrão et al. (2003), os taninos hidrolisáveis são caracterizados por um poliol central, geralmente beta-D-glucose, cujas funções hidroxilas são esterificadas com o ácido gálico. Os taninos hidrolisáveis, apesar de apresentarem comportamento químico similar ao dos fenóis substituídos, possuem certas propriedades indesejáveis, como baixa reatividade com formaldeído, baixo caráter nucleofílico e limitada produção mundial, o que impede que eles sejam utilizados na produção de adesivos fenólicos (PIZZI, 1983; VITAL et al., 2004).

Para a produção dos adesivos à base de taninos, são utilizados os taninos condensados, pois são quimicamente mais estáveis e economicamente mais viáveis. Esses taninos são constituídos de uma mistura de flavonoides polimerizados, de pesos moleculares variados, chamados genericamente de proantocianidinas (Figura 1).

R. Árvore, Viçosa-MG, v.33, n.3, p.521-531, 2009

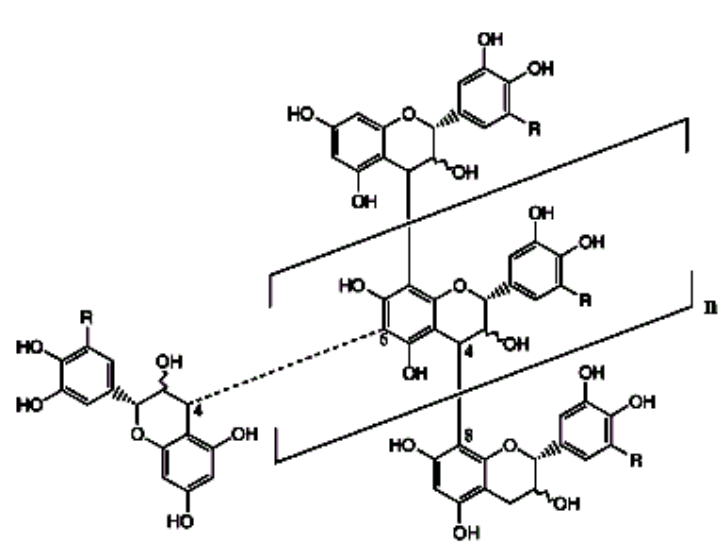

Figura 1 - Modelo de estrutura de um tanino condensado. Figure 1-Model of structure of a condensed tannin.

Os taninos são extraídos principalmente da casca ou do cerne de algumas espécies vegetais. Suas propriedades variam entre espécies ou dentro da mesma espécie, dependendo do tecido vegetal (MORI, 1997). De acordo com Silva (1999), as principais plantas taníferas encontradas no Brasil são: acácia-negra ou mimosa (Acacia mearnsii); barbatimão (Stryphnodendron adstringens); aroeira (Lithraea molleoides); manguevermelho (Rhizophora mangle); quebracho (Schinopsis lorentzzi); goiabeira (Psidium guayava Raddi); murici (Byrsonima verbascifolia Rich); pinheiro (Araucaria angustifolia); eucalipto (Eucalyptus sp.); angicovermelho (Anadenanthera peregrina) e outras.

Visando ao melhor aproveitamento dos resíduos gerados na indústria madeireira, a casca de Anadenanthera peregrina é uma alternativa para a extração de taninos, o que poderá reduzir o volume dos resíduos e dar maior valor agregado às cascas. Após a extração, a casca ainda poderia ser queimada para geração de energia, produção de compostos orgânicos ou outras formas de utilização (MORI, 2000; MORI et al., 2001). 
As pesquisas para desenvolvimento dos adesivos tânicos são extremamente importantes por buscarem alternativas para a indústria de painéis, visto que o custo da aquisição de adesivos sintéticos representa um componente de peso no custo total do produto e também pelo alto percentual de formaldeído presente nos adesivos de uréia-formaldeído, principal aglutinante utilizado na produção de chapas.

Os adesivos à base de taninos, no entanto, apresentam algumas limitações como alta reatividade com o formaldeído, elevada viscosidade, aplicabilidade e resistência à linha de cola. Os três principais fatores que prejudicam a produção desses adesivos são: a) presença de substâncias não tânicas no extrato, como açúcares e gomas; b) a forma e tamanho da molécula tânica reduzem a sua mobilidade, que vai se tornando cada vez menor à medida que prossegue a policondensação; e c) presença do anel éter na estrutura flavonóide, que é hidrofóbico e acarreta aumento na viscosidade dos adesivos.

A viscosidade e a linha de cola fraca e quebradiça, no entanto, podem ser modificadas e os problemas, ser solucionados ou minimizados, através das reações de sulfitação e, ou, hidrólise ácida ou alcalina dos taninos e, também, pela adição dos taninos a outros adesivos sintéticos.

Tendo em vista esses fatores, o objetivo principal deste trabalho foi extrair os taninos da casca de Anadenanthera peregrina, hidrolisá-los, produzir adesivos tânicos e empregá-los para substituir parcial ou totalmente os adesivos à base de uréia-formaldeído na fabricação de chapas de aglomerados.

\section{MATERIAL E MÉTODOS}

Os taninos foram extraídos da casca de angicovermelho (Anadenanthera peregrina), provenientes dos plantios da Universidade Federal de Viçosa, em Viçosa, MG, com 35 anos de idade. A extração foi feita em autoclave à temperatura de $100^{\circ} \mathrm{C}$, por um período de $3 \mathrm{~h}$, adicionando-se à água de extração $3 \%$ de sulfito de sódio. Utilizou-se uma relação licor/casca de 20:1. Depois de extraídos, os taninos foram secos em estufa à temperatura de $70^{\circ} \mathrm{C}$.

Para a produção dos adesivos, os taninos foram dissolvidos em água, com concentração média de 50\%, e levados a uma placa aquecedora com agitação mecânica, na qual foram hidrolisados com ácido clorídrico a 10
$\mathrm{N}$ em pH igual a 3, durante 90 min, à temperatura de $\pm 110^{\circ} \mathrm{C}$. Utilizaram-se $10 \%$ de formaldeído sobre a massa seca de sólidos como agente endurecedor.

\subsection{Propriedades dos adesivos}

O teor de sólidos dos adesivos foi determinado, evaporando-se a água das amostras de $3 \mathrm{~g}$ de adesivo, que foram levadas à estufas até peso constante. O teor de sólidos foi calculado de acordo com Carneiro (2004).

O tempo de gelatinização foi obtido com amostras de $1 \mathrm{~g}$ dos adesivos, que foram colocadas em tubos de ensaio de $15 \mathrm{~cm}$ de altura e $2 \mathrm{~cm}$ de diâmetro, em cujo interior foi mergulhado um bastão de vidro. $\mathrm{O}$ conjunto tubo-bastão foi aquecido até $170^{\circ} \mathrm{C}$, no aparelho gel-time ${ }^{\circledR}$, cronometrando-se o tempo gasto para a polimerização do adesivo.

A viscosidade foi determinada empregando-se um viscosímetro Brookfield-LV (splinder 3) com velocidade de rotação de $12 \mathrm{rpm}$, em amostras de aproximadamente $300 \mathrm{~mL}$, em três repetições.

\subsection{Produção das chapas de aglomerado}

Foram produzidas chapas de partículas com dimensões finais de $40 \times 40 \times 1,00 \mathrm{~cm}$, com madeira de Pinus elliotti, tendo como meta uma densidade de $0,70 \mathrm{~g} /$ $\mathrm{cm}^{3}$. A quantidade de partículas foi calculada com base na massa seca da madeira, na densidade da madeira, na densidade final desejada e na taxa de compactação de 1,4 e em um teor de umidade nas partículas de 3\%.

Fabricaram-se chapas de aglomerado com $8 \%$ de adesivo à base de taninos hidrolisados, bem como chapas com $8 \%$ de adesivo à base de uréia (Cascamite PB 4072 ALBA-Química), adicionados de 12,5\%, 25\% e 37,5\% do adesivo de taninos de angico-vermelho. A mistura das partículas com o adesivo foi realizada em um encolador rotativo, utilizando-se uma pistola pneumática para pulverização do adesivo. As partículas pulverizadas com o adesivo foram pesadas em cada repetição e levadas à caixa formadora. As chapas foram prensadas a_3,2 $\mathrm{MPa}$ e na temperatura de $170^{\circ} \mathrm{C}$, durante $8 \mathrm{~min}$.

Depois de prensadas, as chapas foram acondicionadas à temperatura ambiente até que atingissem umidade de equilíbrio. Os corpos-de-prova para os testes mecânicos e físicos foram retirados das chapas e as suas propriedades, determinadas segundo

R. Árvore, Viçosa-MG, v.33, n.3, p.521-531, 2009 
a norma ASTM D-1037 (1993). Os valores médios de resistência mecânica foram comparados com os valores mínimos exigidos pela norma comercial ANSI/A-208.11993 (American National Standard for Particleboard) e os dos testes físicos, comparados com os valores exigidos pelas normas DIN 68761 (1) - 1961 (SANTANA; PASTORE, 1981), para absorção e inchamento. Vale salientar que, para determinação do inchamento em espessura e absorção de água, utilizou-se o mesmo corpo-de-prova usado para determinação da expansão linear.

O experimento foi instalado, seguindo-se um delineamento inteiramente casualizado com três repetições, num total de 15 painéis, conforme apresentado a seguir.

T1 - Chapas produzidas com $100 \%$ de adesivo de uréia-formaldeído;

T2 - Chapas produzidas com $87,5 \%$ de adesivo de uréia-formaldeído $+12,5 \%$ de adesivo de taninosformaldeído;

T3 - Chapas produzidas com $75 \%$ de adesivo de uréia-formaldeído $+25 \%$ de adesivo de taninosformaldeído;

T4 - Chapas produzidas com $62,5 \%$ de adesivo de uréia-formaldeído $+37,5 \%$ de adesivo de taninosformaldeído; e

T5 - Chapas produzidas com $100 \%$ de adesivo de taninos-formaldeído.

Os resultados foram submetidos à análise de variância (ANOVA). Quando se observaram diferenças significativas, os tratamentos foram comparados entre si, por meio do teste de Tukey a 5\% de significância.

\section{RESULTADOS E DISCUSSÕES}

As propriedades dos adesivos de uréiaformaldeído, taninos-formaldeído e mistura dos dois adesivos estão na Tabela 1 .

Pela Tabela 1, observa-se que a adição do adesivo tânico ao adesivo à base de uréia formaldeído ocasionou redução no teor de sólidos, sendo o tratamento 5 (100\% de adesivo tânico) significativamente diferente dos demais. Não houve diferenças significativas entre o adesivo de uréia-formaldeído e a mistura adesiva contendo $12,5 \%$ de taninos na sua formulação. A redução no teor de sólidos nas composições adesivas, ocasionada pela adição do adesivo tânico era esperada, devido à pequena quantidade de sólidos resinosos presentes na solução, pois a produção desses adesivos com elevados teores de sólidos é limitada pelo grau de polimerização das moléculas tânicas, que elevam demasiadamente a viscosidade na mesma proporção que aumenta o teor de sólidos. Para reduzir a viscosidade e aumentar o teor de sólidos, faz-se necessário a redução drástica do $\mathrm{pH}$ dos taninos, abaixo de 2 , porém essa redução ocasiona uma linha de cola fraca e quebradiça, por desestruturar a molécula tânica.

O tempo de gelatinização do adesivo contendo $100 \%$ de taninos na sua formulação foi significativamente superior ao das demais formulações, apresentando menor velocidade de cura. A menor velocidade de cura desses adesivos se deve, provavelmente, à hidrólise das ligações interflavonóide da molécula tânica, que consequentemente aumentou a reatividade dos taninos com o formaldeído, aumentando-se também a entalpia do processo, conforme foi observado por Carneiro (2006). Não houve diferenças significativas entre os tratamentos $\mathrm{T} 1, \mathrm{~T} 2$ e T3.

Tabela 1 - Propriedades dos adesivos de uréia-formaldeído e taninos-formaldeído de angico-vermelho Table 1 - Urea-formaldehyde and "angico-vermelho" tannin-formaldehyde adhesive properties

\begin{tabular}{|c|c|c|c|c|c|c|c|}
\hline Tratamento & $\begin{array}{c}\text { Taninos- } \\
\text { Formaldeído }(\%)\end{array}$ & $\begin{array}{c}\text { Uréia- } \\
\text { Formaldeído }(\%)\end{array}$ & $\begin{array}{c}\text { Teor } \\
\text { Sólidos }(\%)\end{array}$ & $\begin{array}{c}\text { Tempo } \\
\text { Gelatinização(s) }\end{array}$ & $\begin{array}{c}\text { Viscosidade } \\
\text { (Cp) }\end{array}$ & $\begin{array}{c}\text { Tempo } \\
\text { Trabalho (min) }\end{array}$ & $\mathrm{pH}$ \\
\hline 1 & 0 & 100,0 & $61,3 \mathrm{~A}$ & $33,0 \mathrm{C}$ & $543,3 \mathrm{~A}$ & $54,7 \mathrm{~B}$ & $7,6 \mathrm{~A}$ \\
\hline 2 & 12,5 & 87,5 & $57,0 \mathrm{AB}$ & $31,6 \mathrm{C}$ & $480,0 \mathrm{~B}$ & $61,3 \mathrm{~B}$ & $4,3 \mathrm{~B}$ \\
\hline 3 & 25,0 & 75,0 & $53,2 \mathrm{~B}$ & $35,6 \mathrm{C}$ & $576,7 \mathrm{~A}$ & $43,7 \mathrm{C}$ & $3,7 \mathrm{C}$ \\
\hline 4 & 37,5 & 62,5 & $53,2 \mathrm{~B}$ & $43,0 \mathrm{~B}$ & $580,0 \mathrm{~A}$ & $80,7 \mathrm{~A}$ & $3,7 \mathrm{C}$ \\
\hline 5 & 100,0 & 0 & $45,5 \mathrm{C}$ & $133,3 \mathrm{~A}$ & $290,0 \mathrm{C}$ & $40,0 \mathrm{C}$ & $3,2 \mathrm{C}$ \\
\hline
\end{tabular}

Médias ao longo da coluna seguidas pela mesma letra não diferem entre si, pelo teste Tukey a 5\% de significância.

R. Árvore, Viçosa-MG, v.33, n.3, p.521-531, 2009 
O adesivo formulado com $100 \%$ de taninos de angico-vermelho apresentou a menor viscosidade, e as formulações contendo 25 e $37,5 \%$ de taninos não diferiram do adesivo comercial de uréiaformaldeído (T1).

Uma das grandes dificuldades de produção dos adesivos tânicos é atender à viscosidade para diferentes usos, principalmente onde ele precisa ser aplicado por aspersão através de bicos pulverizadores, requerendo, assim, baixa viscosidade. Neste trabalho, observouse que a hidrólise ácida utilizada para a síntese dos adesivos tânicos foi eficaz para reduzir a viscosidade a valores aceitáveis comercialmente. A baixa viscosidade obtida se deve à hidrólise de substâncias não tânicas presentes na solução e à quebra das ligações interflavonoides do polímero, reduzindo o peso molecular dos taninos, conforme verificado na figura por (MORI, 2000; CARNEIRO, 2006).

De acordo com os resultados de viscosidade obtidos das composições adesivas, observou-se que não houve incompatibilidade entre os dois adesivos, pois esse é um dos principais problemas que normalmente ocorrem quando se faz mistura ou fortificação de adesivos com diferentes polímeros. Caso acorresse incompatibilidade entre eles, provavelmente a viscosidade se elevaria rapidamente ou os adesivos ficariam separados em fases, o que não foi verificado neste experimento. As misturas entre os adesivos tânicos e uréia-formaldeído ficaram homogêneas e a viscosidade, dentro da faixa adequada de aplicação com pistola pneumática.

O tempo de trabalho do adesivo formulado com
$37,5 \%$ de taninos foi significativamente maior que o dos demais adesivos. A formulação contendo $100 \%$ de taninos apresentou o menor tempo de trabalho, não diferindo do tratamento T3 (adesivo contendo 25\% de taninos). O tempo de trabalho das formulações adesivas foi considerado satisfatório, pois a mistura entre os dois adesivos não ocasionou a pré-cura das composições adesivas antes que exercessem suas funções de movimento e mobilidade, bem como sua aplicação através dos bicos pulverizadores. Isso porque, se os dois adesivos reagissem entre si rapidamente, o tempo de trabalho seria baixo, inviabilizando as misturas entre eles. Esse comportamento se deve, provavelmente, ao aumento do caráter nucleofílico dos taninos ocasionado pela quebra das ligações interflavonoides e abertura do anel heterocíclico (CARNEIRO, 2006; PIZZI e MITTAL, 1994).

\subsection{Propriedades Físicas das chapas}

\subsubsection{Densidade e umidade de equilíbrio higroscópico}

Os valores médios das densidades e de umidade de equilíbrio higroscópico das chapas, determinados a $65 \%$ de umidade relativa e temperatura de $\pm 20{ }^{\circ} \mathrm{C}$, estão listados na Tabela 2 . Não se verificou diferença significativa entre as densidades das chapas, indicando bom controle na sua fabricação.

Os teores de umidades observados são compatíveis com aqueles indicados para aglomerado, pela empresa TAFISA, fabricante de painéis de madeira reconstituída (CARNEIRO, 2002).

Tabela 2 - Valores médios de densidade $\left(\mathrm{g} / \mathrm{cm}^{3}\right)$ e umidade $(\%)$ de chapas de aglomerado produzidas com adesivos de uréiaformaldeído e taninos hidrolisados de angico-vermelho

Table 2 - Average values of density $\left(\mathrm{g} / \mathrm{cm}^{3}\right)$ and moisture content $(\%)$ of particleboards produced with urea-formaldehyde and "angico-vermelho" hydrolysed tannin adhesives

\begin{tabular}{|c|c|c|c|c|}
\hline Tratamento & $\begin{array}{l}\text { AdesivoTaninos- } \\
\text { Formaldeído (\%) }\end{array}$ & $\begin{array}{c}\text { AdesivoUréia- } \\
\text { Formaldeído (\%) }\end{array}$ & Densidade $\left(\mathrm{g} / \mathrm{cm}^{3}\right)$ & Umidade $(\%)$ \\
\hline 1 & 0 & 100,0 & 0,67 & $9,10 \mathrm{~B}$ \\
\hline 2 & 12,5 & 87,5 & 0,66 & $10,20 \mathrm{~A}$ \\
\hline 3 & 25,0 & 75,0 & 0,67 & $10,00 \mathrm{AB}$ \\
\hline 4 & 37,5 & 62,5 & 0,68 & $9,86 \mathrm{AB}$ \\
\hline 5 & 100,0 & 0 & 0,69 & $10,23 \mathrm{~A}$ \\
\hline $\mathrm{CV}(\%)$ & & & 3,04 & 3,04 \\
\hline
\end{tabular}

Médias ao longo da coluna seguidas pela mesma letra não diferem entre si, pelo teste Tukey a 5\% de significância. 
A umidade de equilíbrio higroscópico das chapas, determinada a $65 \%$ de umidade relativa e temperatura de $\pm 20^{\circ} \mathrm{C}$, produzidas com adesivo de uréia-formaldeído (T1) foi significativamente menor do que aquela observada nas chapas fabricadas com o adesivo à base de taninos (T5). A maior higroscopicidade dessas chapas foi devida, principalmente, ao caráter hidrofílico das moléculas de taninos que foi ligeiramente aumentado pela hidrólise ácida, pois, de acordo com Sowunmi et al. (2000), a hidrólise ácida tem sido aplicada para quebrar as ligações interflavonoides e, também, abrir o anel heterocíclico, ocorrendo, assim, a formação de um carboncátion com capacidade de reagir com outros nucleofílicos presentes.

Não foram observadas diferenças significativas na umidade de equilíbrio das chapas produzidas com adesivos com 25 e 37,5\% de taninos na sua composição; esses adesivos também não diferiram do adesivo comercial de uréia-formaldeído. Não houve diferença significativa na umidade entre as chapas produzidas com as misturas dos adesivos e as chapas produzidas com adesivo tânico puro.

\subsubsection{Inchamento em espessura, absorção de água e expansão linear}

Na Tabela 3 estão os valores médios de inchamento em espessura e absorção de água após 2 e 24 h de imersão e expansão linear, em chapas produzidas com adesivos de uréia-formaldeído e taninos hidrolisados de angico-vermelho.

As chapas produzidas com as diferentes formulações adesivas incharam e absorveram mais água que o prescrito pela norma. No inchamento em espessura, após 2 e 24 h de imersão em água não houve diferenças significativas entre as chapas produzidas com uréiaformaldeído e com formulações adesivas contendo 12,5\% de adesivo de taninos-formaldeído. As chapas produzidas com adesivos contendo 25 e $37,5 \%$ de taninos incharam menos que as demais. As chapas produzidas apenas com adesivo tânico foram significativamente diferentes e apresentaram o maior inchamento em espessura, devido ao caráter hidrofílico da molécula tânica, que torna os adesivos tânicos suscetíveis à umidade. Normalmente, chapas produzidas com adesivo à base de uréia-formaldeído não resistem à umidade (PIZZI e MITTAL, 1994), e neste experimento tanto as composições quanto o adesivo uréia-formaldeído não a resistiram.
De acordo com Seller (1994), a baixa resistência à umidade dos adesivos à base de uréia é devido à redução da relação molar U-F, deixando grupos livres, portanto reativos para fazer ligações com as moléculas de água. Essa redução na relação molar entre a uréia e o formaldeído fez-se necessário para redução da emissão de formaldeído, principalmente em ambiente fabril.

Para absorção de água, após 2 e 24 h de imersão não houve diferenças significativas entre as chapas produzidas com o adesivo comercial de uréia-formaldeído e aquelas produzidas com a mistura dos dois adesivos. As chapas produzidas apenas com adesivo à base de taninos de angico-vermelho absorveram mais água que aquelas produzidas com a mistura dos adesivos de uréia e taninos. Esse fato se deve, principalmente, à presença dos grupos hidroxila da molécula tânica, que a torna hidrofílica e, consequentemente, faz que o adesivo tânico não resista à umidade, sendo necessários outros procedimentos de produção ou outras modificações da molécula tânica para aumentar a resistência desses grupos à umidade, entre os quais destaca o uso de anidrido acético na mistura racional de forma a bloquear as hidroxilas livres da molécula tânica, inserindo um grupo acetil, hidrofóbico.

Segundo Pizzi e Scharfetter (1978), alternativa para reduz a higroscopicidade seria fazer a quebra das ligações interflavonoides através de "quebradores" de ligações de hidrogênio, em vez de hidrólise ácida, pois a adição de pequenas quantidades de compostos aromáticos de baixo peso molecular que atuam como agentes de "quebra" das ligações de hidrogênio, como fenol, acetato de fenila e naftaleno, permite reduzir a viscosidade das soluções de taninos, sem torná-los mais hidrofílicos, pois não ocorre a abertura do anel heterocíclico.

As chapas produzidas com o adesivo comercial de uréia-formaldeído ultrapassaram os valores máximos de absorção e inchamento permitido pela norma. As chapas produzidas neste trabalho não receberam parafina, o que, provavelmente, diminuiria os valores médios de inchamento em espessura e absorção de água, no curto prazo. A adição de solução de parafina para redução da retenção de água pelas chapas é uma prática comumente utilizada pelas empresas produtoras de aglomerado. Neste estudo, não se adicionou a parafina com o objetivo de avaliar o grau de higroscopicidade das formulações adesivas. 
Tabela 3 - Comparações entre os valores médios de inchamento em espessura, absorção de água após 2 e 24 h de imersão e expansão linear

Table 3 - Comparisons between mean values of thickness swelling, water absorption after 2 and 24 h of immersion and linear expansion

\begin{tabular}{|c|c|c|c|c|c|c|c|}
\hline Tratamento & $\begin{array}{l}\text { Adesivo } \\
\text { T-F }(\%)^{*}\end{array}$ & $\begin{array}{c}\text { Adesivo } \\
\text { U-F }(\%)^{*}\end{array}$ & $\begin{array}{l}\text { Absorção } \\
2 \mathrm{~h}(\%)\end{array}$ & $\begin{array}{c}\text { Absorção (\%) } \\
24 \mathrm{~h}\end{array}$ & $\begin{array}{c}\text { Inchamento } \\
2 \mathrm{~h}(\%)\end{array}$ & $\begin{array}{c}\text { Inchamento } \\
24 \mathrm{~h}(\%)\end{array}$ & $\begin{array}{c}\text { Expansão } \\
\text { Linear }(\%)\end{array}$ \\
\hline 1 & 0 & 100,0 & $72,12 \mathrm{ABC}$ & 88,99 B & $19,60 \mathrm{~B}$ & $25,07 \mathrm{~B}$ & $0,13 \mathrm{C}$ \\
\hline 2 & 12,5 & 87,5 & $80,38 \mathrm{AB}$ & $99,68 \mathrm{AB}$ & $19,20 \mathrm{~B}$ & $26,07 \mathrm{~B}$ & $0,11 \mathrm{C}$ \\
\hline 3 & 25,0 & 75,0 & $57,27 \mathrm{BC}$ & $76,88 \mathrm{~B}$ & $15,23 \mathrm{C}$ & $20,48 \mathrm{C}$ & $0,11 \mathrm{C}$ \\
\hline 4 & 37,5 & 62,5 & $53,86 \mathrm{C}$ & $82,31 \mathrm{~B}$ & $11,64 \mathrm{D}$ & $17,19 \mathrm{C}$ & $0,17 \mathrm{~B}$ \\
\hline 5 & 100,0 & 0 & $84,61 \mathrm{~A}$ & $119,94 \mathrm{~A}$ & $29,65 \mathrm{~A}$ & $56,44 \mathrm{~A}$ & $0,26 \mathrm{~A}$ \\
\hline $\mathrm{CV}(\%)$ & - & - & 13,20 & 11,19 & 6,58 & 5,55 & 8,80 \\
\hline Norma & - & - & $<10$ & $<15$ & $<6$ & $<15$ & $<0,35$ \\
\hline
\end{tabular}

Médias ao longo da coluna seguidas pela mesma letra não diferem entre si, pelo teste Tukey a 5\% de significância

* Adesivos de uréia-formaldeído (U-F) e taninos hidrolisados de angico-vermelho (T-F).

Haselein et al. (2002), citados por Fernandes et al. (2003), obtiveram resultados de 66,45\% para absorção de água em 24 h e $29,18 \%$ de inchamento em espessura para $24 \mathrm{~h}$, com chapas de aglomerados fabricadas com $8 \%$ de adesivo à base de taninos de acácia-negra e com $1 \%$ de parafina. Os valores médios de absorção e inchamento, encontrados por esses autores, são menores que os observados nas chapas produzidas apenas com o adesivo à base de taninos de angicovermelho.

Os valores médios de expansão linear ficaram abaixo do máximo permitido pela norma ANSI/A1-280/93, mostrando a estabilidade das chapas produzidas nos diferentes tratamentos.

De acordo com a Tabela 3, até $25 \%$ de substituição na composição adesiva a estabilidade dimensional das chapas foi mantida nos mesmos padrões das chapas produzidas com o adesivo comercial, não existindo diferenças estatísticas entre as chapas produzidas com adesivo comercial de uréia-formaldeído e aquelas confeccionadas com adesivos contendo 12,5 e $25 \%$ de taninos na sua formulação. Acima de $25 \%$ de substituição ocorreu queda na estabilidade, sendo mais intensa nas chapas produzidas apenas com o adesivo à base de taninos. Apesar de as chapas produzidas apenas com adesivo de taninos serem menos estáveis, ainda ficaram dentro dos padrões de qualidade.

\subsection{Propriedades mecânicas das chapas}

Os valores médios das propriedades mecânicas das chapas são apresentados na Tabela 4 .

Tabela 4 - Comparações entre os valores médios das propriedades mecânicas das chapas produzidas com adesivos de uréiaformaldeído (U-F) e taninos hidrolisados de angico-vermelho (T-F)

Table 4-Comparisons between the mean values of the mechanical properties of the boards produced with urea-formaldehyde adhesives $(U-F)$ and hydrolysed tannins of "angico-vermelho" (T-F)

\begin{tabular}{cccccccr}
\hline Tratamento & $\begin{array}{c}\text { Adesivo } \\
\text { T-F }(\%)^{*}\end{array}$ & $\begin{array}{c}\text { Adesivo } \\
\text { U-F }(\%)^{*}\end{array}$ & $\begin{array}{c}\text { Tração Perpendicular } \\
(\mathrm{MPa})\end{array}$ & $\begin{array}{c}\text { Arrancamento } \\
\text { Parafuso (N) }\end{array}$ & $\begin{array}{c}\text { Dureza } \\
\text { Janka(N) }\end{array}$ & $\begin{array}{c}\text { MOR } \\
(\mathrm{MPa})\end{array}$ & $\begin{array}{r}\text { MOE } \\
(\mathrm{MPa})\end{array}$ \\
\hline 1 & 0 & 100,0 & $0,78 \mathrm{~A}$ & $1264 \mathrm{~A}$ & $5441 \mathrm{~B}$ & $19,96 \mathrm{~A}$ & $2329 \mathrm{~A}$ \\
2 & 12,5 & 87,5 & $0,67 \mathrm{AB}$ & $1186 \mathrm{~B}$ & $4850 \mathrm{C}$ & $17,34 \mathrm{~B}$ & $1742 \mathrm{CD}$ \\
3 & 25,0 & 75,0 & $0,80 \mathrm{~A}$ & $1210 \mathrm{~B}$ & $6443 \mathrm{~A}$ & $18,25 \mathrm{AB}$ & $1659 \mathrm{D}$ \\
4 & 37,5 & 62,5 & $0,70 \mathrm{AB}$ & $1283 \mathrm{~A}$ & $6379 \mathrm{~A}$ & $20,03 \mathrm{~A}$ & $2019 \mathrm{~B}$ \\
5 & 100,0 & 0 & $0,54 \mathrm{~B}$ & $1118 \mathrm{C}$ & $6655 \mathrm{~A}$ & $17,11 \mathrm{~B}$ & $1924 \mathrm{BC}$ \\
\hline $\mathrm{CV}(\%)$ & - & - & 11,09 & 1,44 & 3,15 & 5,20 & 4,10 \\
\hline Norma & - & - & $>0,40$ & $>900$ & $>2225$ & $>12,5$ & $>1900$ \\
\hline
\end{tabular}

Médias ao longo da coluna seguidas pela mesma letra não diferem entre si, pelo teste Tukey a 5\% de probabilidade.

* Adesivos de uréia-formaldeído (U-F) e taninos hidrolisados de angico-vermelho (T-F). 


\subsubsection{Tração perpendicular}

Os valores médios de tração perpendicular estão apresentados na Tabela 4. A resistência à tração perpendicular dos diferentes adesivos ultrapassou o valor mínimo exigido pela norma ANSI. Não houve diferenças significativas entre o adesivo de uréiaformaldeído e aqueles produzidos com a mistura dos dois adesivos. No entanto, a chapa produzida apenas com adesivo à base de taninos foi significativamente menos resistente que aquelas produzidas com uréiaformaldeído; apesar disso, o valor destas últimas ainda foi superior ao valor mínimo estabelecido pela norma. Com exceção do adesivo produzido com $25 \%$ de taninos (T3), não se observou diferença estatística entre as chapas produzidas com adesivo de taninos puro e aquelas produzidas com mistura dos dois adesivos.

A resistência à tração perpendicular evidenciada nas chapas produzidas com o adesivo tânico e também com as suas misturas se deve, provavelmente, à hidrólise dos taninos que promoveu, além das quebras das ligações interflavonoides, a hidrólise das substâncias não tânicas, favorecendo a redução da viscosidade e, consequentemente, facilitando as funções de movimento e mobilidade dos adesivos no substrato, favorecendo a adesão entre as partículas.

Esses resultados são superiores aos obtidos por Hillig et al. (2002), que encontraram valores médios de tração perpendicular $(0,196 \mathrm{MPa})$ para chapas fabricadas com taninos de acácia-negra, que é um valor abaixo do mínimo exigido nos padrões de qualidade. Calegari et al. (2004) produziram chapas de aglomerado fabricadas com adesivo de taninos de acácia-negra, com resistência à tração igual a $0,572 \mathrm{MPa}$.

De modo geral, entre os tratamentos avaliados a melhor resistência à tração perpendicular foi obtida nos tratamentos contendo $75 \%$ de adesivo de uréia $+25 \%$ de adesivo de taninos em sua formulação, com resistência média de $0,8 \mathrm{MPa}$.

\subsubsection{Arrancamento de parafuso}

Observa-se, na Tabela 4, que os valores médios de resistência ao arrancamento de parafuso em todas as composições adesivas ultrapassaram o valor mínimo exigido pela norma e não houve diferenças significativas entre o adesivo de uréia-formaldeído (T1) e o adesivo contendo 37,5\% de taninos hidrolisados (T4). Não houve diferenças significativas entre os adesivos contendo
12,5 ou $25 \%$ de taninos na sua formulação. A resistência ao arrancamento de parafuso para o adesivo (T5), produzido apenas com taninos, foi menor que a dos demais tratamentos. Vale ressaltar que, apesar de não ter resistência ao arrancamento igual ao adesivo uréiaformaldeído, as chapas produzidas com taninos apresentaram resistência ao arrancamento superior ao mínimo estabelecido pela norma.

Esses resultados são superiores aos observados por Hillig et al. (2002), que encontraram valores médios de arrancamento de parafuso de $220 \mathrm{~N}$ para chapas de Pinus, fabricadas com taninos de acácia-negra.

A resistência das chapas ao arranque do parafuso está associada com o grau de adesão entre as partículas, pois, quanto menor for a resistência à ligação interna, menor será a força exigida para a retirada do parafuso, conforme pode ser observado na Tabela 4. Uma boa adesão entre as partículas dificulta a saída do parafuso no interior da chapa, necessitando de uma força maior para retirá-lo.

Essa propriedade é de grande importância para a indústria moveleira, principalmente, na fixação de puxadores de portas e gavetas.

\subsubsection{Dureza Janka}

Os valores médios de dureza Janka para todas as composições adesivas ultrapassaram o valor mínimo exigido pela norma, e não houve diferença significativa entre as chapas produzidas com 25, 37,5 e 100\% de taninos em sua formulação. Porém, as chapas produzidas com adesivo (T2) contendo em sua formulação 12,5\% de taninos foram significativamente menos resistentes do que as demais.

O valor médio de dureza Janka para as chapas produzidas com o adesivo de uréia-formaldeído foi significativamente menor que as produzidas com a mistura dos dois adesivos, com exceção da composição adesiva contendo $12,5 \%$ de taninos. De modo geral, a adição do adesivo de taninos aumentou a dureza das chapas e se deveu, provavelmente, à redução do polímero com a cura não somente pela perda de água da mistura, mas também pela eliminação da água formada durante a reação de condensação e polimerização. E a formação de ligações metilênicas, resultantes da condensação, também produz o encolhimento da estrutura do polímero, aproximando as cadeiras e as partículas, o que consequentemente pode estar contribuindo para o aumento da dureza das chapas. 
Comparando os valores médios de dureza Janka observados neste experimento com os dados obtidos por Calegari et al. (2004) para chapas coladas com adesivo tânico de acácia-negra, verifico-se que os valores médios obtidos neste experimento são maiores que os encontrados em acácia-negra, no qual foi observado valor de dureza igual a $3484 \mathrm{~N}$.

\subsubsection{Módulo de ruptura (MOR)}

Os valores médios apresentados na Tabela 4 indicaram que o módulo de ruptura de todas as chapas apresentaram valores acima da norma ANSI/A1-280/ 93, que estabelece o valor mínimo de $12,5 \mathrm{MPa}$ para painéis de madeira aglomerada, de média densidade. A resistência obtida pelas chapas produzidas com adesivos formulados com taninos se deve, principalmente, à baixa viscosidade dos adesivos ocasionada pela hidrólise ácida, que também promoveu a quebra das ligações interflavonoides e a hidrólise das substancias não tânicas, contribuindo para maior reatividade entre os taninos e o formaldeído, formando ligações cruzadas nas posições reativas disponíveis, conforme descrito por Pizzi e Mittal (1994). As chapas produzidas com o adesivo de uréia-formaldeído puro e aquelas fabricadas com composição adesiva, contendo $37,5 \%$ de taninos, foram significativamente mais resistentes que as chapas confeccionadas com as demais misturas dos adesivos.

Não houve diferenças significativas no módulo de ruptura entre as chapas produzidas com a formulação adesiva contendo 12,5 e $25 \%$ de taninos e aquelas produzidas com $100 \%$ de taninos. Nas chapas feitas com a mistura dos dois adesivos, verificou-se ligeiro aumento na resistência com o aumento da porcentagem de taninos na formulação do adesivo.

Hillig et al. (2002) encontraram valores médios de módulo de ruptura de 18,61 MPa para chapas fabricadas com adesivos de taninos de acácia-negra. Os valores observados no módulo de ruptura neste experimento foram próximos aos encontrados nas chapas fabricadas com tanino comercial de acácia-negra, evidenciandose o efeito positivo da hidrólise ácida dos taninos de angico-vermelho para a formulação dos adesivos.

\subsubsection{Módulo de elasticidade (MOE)}

Analisando os valores médios de módulo de elasticidade, observou-se que as chapas produzidas com adesivos contendo 12,5 e $25 \%$ de taninos não atingiram o valor mínimo preconizado pela norma. Não houve diferenças significativas entre as chapas produzidas com formulações adesivas contendo 37,5 e $100 \%$ de taninos. Também, não foram constatadas diferenças significativas entre as chapas produzidas com 12,5 e $25 \%$ de taninos na formulação do adesivo.

Chapas produzidas com adesivo de uréiaformaldeído foram significativamente mais rígidas do que aquelas fabricadas com o adesivo à base de taninos. Observou-se que, de modo geral, os valores médios da rigidez das chapas ficaram próximos ao mínimo estabelecido, e esses baixos valores são devidos, principalmente, à característica vítrea desses adesivos após polimerizados.

Fechtal e Riedl (1993) encontraram valores médios de 3040 MPa para MOE em chapas de partículas fabricadas com adesivo de taninos de Acacia mollissima. Vale ressaltar que a densidade média dessas chapas foi de $0,85 \mathrm{~g} / \mathrm{cm}^{3}$ e que, geralmente, um incremento na densidade da chapa provoca aumento da resistência à flexão e à tração. Hillig et al. (2002) encontraram valores médios de módulo de elasticidade de $2746 \mathrm{MPa}$, em chapas fabricadas com taninos de acácia-negra.

Carneiro et al. (2004), pesquisando a combinação do adesivo à base de taninos e o adesivo de uréiaformaldeído, encontraram valores médios de módulo de elasticidade de $3240 \mathrm{MPa}$ em chapas produzidas com adesivo formulado com $50 \%$ de uréia-formaldeído $+50 \%$ de adesivo de taninos. Os referidos autores produziram os adesivos com taninos hidrolisados e sulfitados, o que pode ter contribuído para aumentar a rigidez das chapas em relação aos valores obtidos neste experimento.

\section{CONCLUSÕES}

A resistência mecânica das chapas de aglomerados produzidas com o adesivo à base de taninos de angicovermelho ultrapassou os valores mínimos requeridos pela norma ANSI/A1-280/93. A adição de até 25\% de taninos ao adesivo uréia-formaldeído ocasiona redução no módulo de elasticidade. A combinação dos adesivos tânicos com os adesivos à base de uréia-formaldeído ocasionou aumento em algumas propriedades mecânicas. As chapas mostraram boa estabilidade dimensional, apresentando valores abaixo do máximo permitido.

Quanto à absorção de água e ao inchamento em espessura, após 2 e 24 h de imersão todas as chapas excederam o valor máximo permitido.

R. Árvore, Viçosa-MG, v.33, n.3, p.521-531, 2009 
Os resultados deste trabalho indicam que os adesivos de taninos de angico-vermelho podem substituir parcial ou totalmente o adesivo comercial de uréia, por apresentar viscosidade adequada para aplicação em chapas de aglomerado, por conter menor percentual de formaldeído na sua composição e menor custo de produção, visto que são produzidos a partir de cascas, que é um resíduo geralmente descartado pelas madeireiras. Depois da extração, a casca, ainda, poderia ser queimada para geração de energia, produção de compostos orgânicos ou outras formas de utilização.

$\mathrm{O}$ adesivo à base de taninos de angico-vermelho e também as suas misturas com o adesivo comercial de uréia-formaldeído são indicados para uso interior, em que a resistência à umidade não é requerida.

Em razão desses resultados, recomendam-se medidas e, ou, tratamentos que visem à redução de absorção de água pelas chapas, como o uso de parafina para impermeabilizar a superfície e também a incorporação do adesivo de taninos nos adesivos à base de fenol, uma vez que são resistentes à umidade. Recomendase, também, a adição de diferentes anidridos ao adesivo tânico, visando ao bloqueio dos grupos hidroxílicos da molécula de taninos, o que pode acarretar redução na higroscopicidade do adesivo e, consequentemente, reduzir a absorção de água pelas chapas.

\section{REFERÊNCIAS}

AMERICAN NATIONAL STANDARD - ANS. Matformed wood particleboard: specification ANSI/A 208.1.1993. Gaithersburg: National Particleboards Association, 1993. 9p.

\section{AMERICAN SOCIETY FOR TESTING AND} MATERIALS - ASTM. Annual Book of ASTM Standards: Philadelphia: ASTM D1037, v.04.09, 1993.

CALEGARI, R. et al. Adição de aparas de papel reciclável na fabricação de chapas de madeira aglomerada. Revista Ciência Florestal, v.14, n.1.p.193-204, 2004.

CARNEIRO, A. C. O. et al. Propriedades de chapas de flocos fabricadas com adesivo de uréiaformaldeído e de taninos da casca de Eucalyptus grandis W. Hill ex Maiden ou de Eucalyptus pellita F. Muell. Revista Árvore, v.28, n.5. p.715-724, 2004.

R. Árvore, Viçosa-MG, v.33, n.3, p.521-531, 2009
CARNEIRO, A. C. O. Efeito da sulfitação dos taninos de $E$. grandis $e$. pellita para produção de chapas de flocos. 2002. $91 \mathrm{f}$. Dissertação (Mestrado em Ciência Florestal) Universidade Federal de Viçosa, Viçosa, MG, 2002.

CARNEIRO, A. C. O. Efeito da hidrólise ácida e sulfitação de taninos de Eucalyptus grandis W. Hill ex Maiden $e$ Anadenanthera peregrina Speg., nas propriedades dos adesivos. 2006. $182 \mathrm{f}$. Tese (Doutorado em Ciência Florestal) Universidade Federal de Viçosa, Viçosa, MG, 2006.

FERNANDES, M. M. et al. Avaliação da qualidade de chapas de partículas manufaturadas com resina tanino-formaldeido. Revista Floresta e Ambiente, v.10, n.2, p.100-104, 2003.

FECHTAL, M.; RIEDL, B. Use of Eucalyptus and Acacia molissima bark extract-formaldehyde adhesives in particleboard manufacture.

Holzforschung, v.47, n.4, p.349-357, 1993.

FERRÃO, M. F. et al. Técnica não destrutiva de análise de tanino em café empregando espectroscopia no infravermelho e algoritmo genético. Tecno-Lóg, v.7, n.1, p.9-26, 2003.

HILLIG, E.; HASELEIN, C. R.; SANTINI, E. J. Propriedades mecânicas de chapas aglomeradas estruturais fabricadas com Madeira de Pinus, Eucalipto e Acácia-negra. Revista Ciência Florestal, v.12, n.1, p.59-70, 2002.

MORI. C. et al. Uso de taninos de três espécies de Eucalyptus na produção de adesivos para colagem de madeira. Revista Árvore, v.25, n.1, p.19-28, 2001.

MORI, F. A. Uso de Taninos da casca de Eucalyptus grandis para produção de adesivos de madeira. 1997. 47f. Dissertação (Mestrado em Ciência Florestal) - Universidade Federal de Viçosa, Viçosa, MG, 1997.

MORI, F. A. Caracterização parcial dos taninos da casca e dos adesivos de três espécies de eucaliptos. 2000. 73f. Tese (Doutorado em Ciência Florestal) - Universidade Federal de Viçosa, Viçosa, MG, 2000.

PIZZI, A. Wood adhesives: chemistry and technology. New York: Marcell Dekker, 1983. 364p. 
PIZZI, A. Urea-formaldehyde adhesives In: PIZZI, A.; MITTAL, K. L. Handbook of adhesive technology. New York: Marcel Dekker, 1994b. p.381-392.

PIZZI, A.; SCHARFETTER, H. The chemistry and development of tannin-based adhesives for exterior plywood. Journal of Applied Polymer Science, 22:1745-1761, 1978.

SANTANA, M. A. E.; PASTORE, J. F. Adesivo de tanino-formaldeído para aglomerados. Brasília: Instituto Brasileiro de Desenvolvimento Florestal, 1981. (Série Técnica, 2).

SELLERS, T. Adhesives in wood industry. In: PIZZI, A.; MITTAL, K. L. Handbook of adhesive technology. New York: Marcel Dekker, 1994. p.599-614
SILVA, T. S. S. Estudo de tratabilidade físico-química com uso de taninos vegetais em água de abastecimento e esgoto. 1999. 88f. Dissertação (Mestrado em Saúde Pública) - Fundação Oswaldo Cruz, São Paulo, 1999.

SOWUNMI, S. et al. Differential scanning calorimetry of hydrolysed mangrove tannin. Polymer International, v.49, p.574-578, 2000.

WATERMAN, P. G.; MOLE, S. Analysis of phenolic plant metabolites. London: Blackwell Scientific Publications, 1994. 238p.

VITAL, B. R. et al. Adesivos à base de taninos das cascas de duas espécies de eucalipto para produção de chapas de flocos. Revista Árvore, v.28, n.4, p.571-582, 2004. 
